\title{
Prácticas de parentesco y configuración de espacios colectivos de vida en el área tseltal cafetalera, Tenejapa, Chiapas
}

\author{
Kinship Practices and the Configuration of Spaces for Collective Living \\ in the Tseltal Coffee Area, Tenejapa, Chiapas
}

Edith Cervantes Trejo

SERVICIOS DE CAPACITACIÓN Y ASESORÍA PARA EL DESARROLLO, S.C., edithcervantest@gmail.com

\section{Erin Ingrid Jane Estrada Lugo}

EL COLEGIO DE LA FRONTERA SUR, eestrada@ecosur.mx

\section{Eduardo Bello Baltazar \\ EL COLEGIO DE LA FRONTERA SUR, ebello@ecosur.mx}

Se indaga cómo las prácticas de residencia patrilocal y de herencia patrilineal de la tierra realizadas por grupos de parentesco repercuten en la construcción de los espacios donde ellos residen y trabajan. La espacialidad de tales prácticas de parentesco, asentadas en una noción de propiedad colectiva del territorio, contribuye a una intensa interacción social en los encuentros cotidianos o periódicos que realizan los miembros del grupo en esos lugares, los cuales se configuran como espacios colectivos de vida o sedes colectivas. En estas sedes suele ocurrir una amplia socialización de conocimientos. La investigación se inscribe en la generalización analítica de los estudios de caso. Se pretende que la construcción teóricaempírica del papel de las prácticas de parentesco en la organización del territorio de las comunidades cafetaleras tseltales sea transferible a situaciones análogas y contribuya a una mayor comprensión de la dinámica de las comunidades indígenas.

Palabras Clave: parentesco, residencia y herencia, sede, espacios colectivos.

This essay examines how the practices of patrilocal residence and patrilineal inheritance of land among Tseltal kinship groups impact the construction of the spaces in which they live and work. The spatiality of these kinship practices, based on the principle of collective land ownership, generates an intense social interaction in the daily, or periodic, meetings that group members hold in those places, which are configured as spaces for collective living, or collective seats. These seats thus tend to become spaces in which broad processes of the socialization of knowledge occur. Research was conducted from the perspective of analytical generalizations based on case studies, and seeks to make the theoretical-empirical construction of the role of kinship practices in the organization of the territory of these Ttseltal coffee-growing communities transferable to similar situations, while also contributing to a better understanding of the dynamics of indigenous communities.

KEYwORDs: kinship, residence and inheritance, seat, collective spaces.

Fecha de recepción del artículo: 9 de marzo de 2015 / Fecha de aprobación: 3 de agosto de 2015 / Fecha de recepción de la versión final: 9 de septiembre de 2015 


\section{INTRODUCCIÓN*}

1 café se introduce en las regiones indígenas durante la década de 1970 , a partir de la promoción institucionalizada de la cafeticultura en nuestros país por parte del Instituto Mexicano del Café (Inmecafé), que realizó una introducción masiva de este cultivo en las zonas montañosas del sureste mexicano, las más aptas para su desarrollo y asiento de numerosos pueblos indígenas (Nolasco 1985, 93; Pérez-Grovas et al. 2002, 33). Con el fin de incrementar las cuotas de exportación del grano, y en el marco de la revolución verde, este organismo instituye en los minifundios de los pequeños productores el monocultivo de café con sombra monoespecífica con un alto uso de insumos químicos; las organizaciones sociales campesinas e indígenas, creadas a raíz de la desaparición de este organismo, tuvieron que remontar las problemáticas del cambio de manejo del cultivo hacia la producción orgánica, el procesamiento del grano y su comercialización (Pérez-Grovas 1998, 20, 44).

La producción del café orgánico en nuestro país, sustentada por numerosos pueblos indígenas, es de suma importancia, ya que contribuye al mantenimiento de la biodiversidad, a la conservación de suelos y cuencas hidrológicas, y a la mejora de la calidad de vida de quien lo produce. Sin embargo, poco se conoce sobre la dinámica de los mecanismos sociales que sostienen tal proceso. Entre ellos, la articulación social a diferentes niveles, local o global, que genera la organización cafetalera para su mantenimiento, cómo ésta se entrelaza con el parentesco -considerando que el sustrato social de donde ésta emerge es predominantemente indígena-, para dar como resultado, como señala Pérez-Grovas et al. $(2002,37)$, que México sea el mayor productor mundial de café orgánico derivado de los esfuerzos de las organizaciones de pequeños productores de café de áreas indígenas.

*Agradezco al Consejo Nacional de Ciencia y Tecnología (Conacyt) por la beca otorgada para la realización de esta investigación; y al Colegio de la Frontera Sur, Unidad San Cristóbal por las facilidades para llevarla a cabo. 
El artículo explora aspectos del tejido social indígena que están en la base de los procesos de socialización de conocimientos de café orgánico. Se enfoca en el análisis de las prácticas realizadas por grupos de parentesco que inciden en la construcción de espacios colectivos al interior de sus ámbitos de residencia y productivos, los cuales subyacen a la socialización de ese tipo de conocimiento al interior de comunidades del área tseltal de la región de Los Altos de Chiapas. Los grupos de parentesco tienen la peculiaridad de estar constituidos frecuentemente por tres generaciones de lazo patrilineal, y las familias nucleares que los conforman, constituidas generalmente por padres e hijos, habitan casas contiguas configurando una unidad de residencia. Puesto que las prácticas orgánicas a nivel parcelario se realizan por el conjunto del grupo, y no por un productor individual o de una familia aislada, al ser replicadas por los grupos de parentesco adscritos a una organización cafetalera se alcanza una amplia cobertura social y territorial en este tipo de producción. El nexo entre el entramado del tejido social indígena y la novísima producción orgánica desvela rasgos de contemporaneidad de los pueblos originarios tseltales, los cuales conforman uno de los dos grandes bloques lingüísticos mayances que forman la región alteña; particularmente, el área tseltal se extiende a parte de las regiones de las montañas marginales del este y norte de Chiapas.

Se exponen los resultados de investigación de dos grupos de parentesco miembros de la organización cafetalera tseltal denominada "Productores de Café Orgánico de Kotolté", ubicadas en las comunidades de Kotolté y Los Mangos del municipio de Tenejapa, Chiapas, dos de las cuatro comunidades de su área de influencia. Esta organización se constituye legalmente en el 2006 y realiza la comercialización colectiva de café orgánico a través de la Unión de Ejidos San Fernando, cuya sede está en la localidad zoque y municipio del mismo nombre, en el estado de Chiapas.

La investigación se enmarca en la validez de los estudios de caso, considerando que "un estudio de caso es una indagación empírica que investiga un fenómeno contemporáneo -el 'caso'- en profundidad y en el contexto de la vida real, especialmente cuando los límites entre el fenómeno y el contexto no son claramente evidentes" 
(Yin 2009, 16). Los dos grupos de parentesco -que integran el estudio de caso- son ejemplos de los grupos compuestos por tres generaciones de lazo patrilineal observados empíricamente en la región alteña (Villa Rojas 1992; Vogt 1966; Collier 1976; Ixtacuy et al. 2006). El "caso" -el fenómeno-, la relación entre las prácticas de residencia y herencia que realizan estos grupos de parentesco y la configuración de espacios colectivos en comunidades tseltales cafetaleras alteńas se indaga a través de las categorías analíticas de sede, uso del espacio y la aplicación de reglas y recursos que estructuran a la práctica social considerando contextos específicos (Giddens 2001 y 2011), que se asocian a las unidades de observación correspondientes a los ámbitos de propiedad de residencia y productivos del grupo -considerados como espacios lindados-, la aplicación de principios patrilineales en las prácticas de parentesco por los miembros del grupo y los contextos en que algunos no los cumplen. Las prácticas de producción de datos se basaron en la elaboración de genealogías y soportes gráficos de las configuraciones, entrevistas semiestructuradas, observación directa y diario de campo, y se realizaron durante los años 2013 y 2014. La relación entre categorías y unidades de observación obedece a que ningún caso tiene significado en sí mismo y por sí mismo, sino por referencia a una teoría o categoría analítica (Giménez 2012, 44). La investigación se inscribe en la generalización analítica de los estudios de caso, o en otras palabras, en la posibilidad de que el constructo teórico del papel de las prácticas de parentesco en la constitución de los espacios de residencia y productivo de los asentamientos tseltales sea transferible a situaciones análogas, con el fin de abundar a una mayor comprensión de los principios organizativos de la vida de la comunidad. $^{1}$

${ }^{1}$ La generalización analítica es un término acuñado por Yin $(2009,15)$ y es distinta a la generalización estadística que refiere a la "inferencia realizada a partir de una muestra estadísticamente representativa [...] en donde se trata de enumerar frecuencias" (Giménez op. cit., 49). La generalización analítica, señala Yin $(2009,37,116)$, se usa para designar a la generalización de los estudios cualitativos y apunta a una teoría del fenómeno estudiado que puede ser transferible a otros casos o refinada a la luz de ellos. 
En los primeros apartados se discute cómo los procesos de residencia patrilocal y herencia patrilineal de la tierra inciden en la constitución de los propios espacios donde el grupo de parentesco vive y trabaja, los cuales se distinguen por ser sedes colectivas que propician una constante interacción entre sus miembros. Se caracterizan las configuraciones de las sedes de los ámbitos de residencia y productivo del grupo y se realiza una aproximación a los escenarios de interacción donde ocurren los encuentros cotidianos o temporales de sus miembros vinculados a múltiples prácticas, entre las que se encuentran las relacionadas con la comunicación de conocimientos de café orgánico y su aplicación en el manejo agrícola de la parcela. La agencia del grupo de parentesco en la organización de un espacio-tiempo social (Giddens 2011, 285) de sus miembros se identifica al abordar al grupo como sistema de interacción y a la práctica como interacción social, la cual está integrada por relaciones de poder, moralidad y comunicación de sentido (Giddens 2001, 150). La noción de poder aquí se aplica como la capacidad transformadora de la acción social, y se concreta en la movilización o aporte de recursos aplicados como medios en la interacción, constituyendo el "puede" que media entre intenciones y necesidades (Giddens 2001, 137-138). La moralidad en una interacción implica el empleo de normas consideradas como procedimientos de acción que se aplican a la reproducción de prácticas sociales (Giddens 2011, 57). Y la comunicación de sentido está permeada por el uso de esquemas interpretativos, por los cuales los participantes se explican lo que cada uno dice y hace (Giddens 2001, 150). En el sistema de interacción, los miembros del grupo son actores en copresencia que se caracterizan por la posesión de "una gran cantidad de conocimientos (prácticos) sobre lo que hacen, las circunstancias en las que lo hacen, y las reglas y recursos que lo posibilitan" (Santoro 2003, 243). Si el sistema de interacción del grupo de parentesco se proyecta en un plano de mayor temporalidad, se revela entonces como una de las fases del ciclo de desarrollo de los grupos domésticos, que en su conjunto expresa un peculiar proceso de reproducción social anclado en principios patrilineales de herencia y residencia, acorde con pautas específicas de la cultura mesoamericana, esta temática se expone en el último apartado. 


\section{Prácticas de PARENTESCO Y CONFIGURACIÓN DE ESPACIOS COLECTIVOS DE VIDA}

En Los Altos de Chiapas, incluida el área tseltal cafetalera, los hombres casados construyen su casa cerca de la vivienda de sus padres derivado de la práctica de residencia patrilocal, de tal manera que la casa de los ancianos abuelos se encuentra rodeada por otras pertenecientes a sus hijos y a su descendencia, se conforma así un grupo de parentesco constituido por tres generaciones de lazo patrilineal. ${ }^{2}$ Nutini $(1976,17)$ señala que esos grupos corresponden a linajes mínimos, grupos de poca profundidad genealógica, que generalmente tienen una unidad residencial en una área circunscrita.

Estos grupos observados empíricamente por destacados antropólogos a lo largo y ancho de la Mesoamérica contemporánea han sido generalmente conceptuados a partir de la terminología de parentesco, lo que ha conducido a graves distorsiones en la información etnográfica (Robichaux 2005a, 190), y ha descuidado la parte significativa que tiene la residencia en la estructura de las unidades sociales de parentesco (Nutini 1976, 7-8). Robichaux sostiene que la conceptualización de estos grupos localizados de parentesco no se logra a través de identificar las reglas jurídicas de parentesco, las normas ideales, sino que es necesario referirse a sus prácticas o conjunto de valores que los reproducen, que tienen como base los principios patrilineales de residencia y herencia (Robichaux 2005a, 168, 202). La indagación empírica de las prácticas de residencia y herencia de los grupos de parentesco tseltales, objeto de estudio, efectivamente apuntan en la dirección de que son operadas bajo ese patrón de principios patrilineales, aunque algunos de sus miembros no los cumplen cabalmente, como lo ilustran más adelante los grupos de Kotolté y Los Mangos, y otras referencias del área tsotsil de la región alteńa, en el caso de las hijas casadas que viven en la casa de sus padres, lo cual origina que la residencia patrilocal se flexibilice ante los nuevos contextos comunitarios, por ejemplo, la migración de sus cónyuges en búsqueda de trabajo.

${ }^{2}$ Entre los investigadores que a nivel empírico encuentran estos grupos de parentesco en la región alteńa se tiene a Villa Rojas 1992; Vogt 1966; Collier 1976. 
El artículo explora el papel de las prácticas de parentesco ya señaladas en la organización social y del territorio de las comunidades tseltales alteñas, considerándolas como procesos sociales que sustentan configuraciones territoriales y como acciones de actores reflexivos. Con ello se pretende contribuir al entendimiento de los usos del parentesco en relación con la organización del espacio (Estrada $2011,21)$, así como a una mayor comprensión de esta unidad social empírica de tres generaciones de lazo patrilineal, que denominamos grupo localizado de parentesco. ${ }^{3}$ Esta unidad de parentesco intermedia que opera entre el grupo doméstico y la comunidad mantiene importantes funciones sociales, rituales o económicas locales (Nutini 1976, 14-17), y es considerada como la unidad fundamental de la organización social de miles de comunidades en la Mesoamérica contemporánea (Robichaux 2005a, 203). ${ }^{4}$

El emplazamiento de las casas de hijos casados en los terrenos que el padre ha cedido dentro de su vecindario, derivado del proceso de residencia patrilocal, refuerza y conserva una configuración territorial constituida por espacios habitacionales contigüos. A la vez, la práctica de herencia patrilineal de la tierra, que conlleva un proceso de parcelamiento del espacio productivo de la pareja parental del grupo paralelo al usufructo de la parcela heredada por parte del grupo doméstico de cada hijo casado, sustenta la configuración de un terreno parcelado compacto que tiende a un mismo uso del suelo. Así, las prácticas reproducidas de parentesco en cuestión, vistas como procesos sociales, sustentan las formas espaciales de los ámbitos de residencia y productivo del grupo que acusan regularidad y recurrencia en las comunidades cafetaleras alteñas. ${ }^{5}$ La contigüidad de los terrenos donde se ubican las viviendas y los minifundios de las plantaciones de café de los grupos domésticos que integran al grupo de parentesco permite la libre movilidad de sus miembros, y posibilita su constante

${ }^{3}$ Este término lo adoptamos de Robichaux (2005a, 168, 172).

${ }^{4}$ En el área maya, durante la época colonial Peniche (2003) identifica a los chibales, grupos de filiación que Bracamonte y Sosa (2000) asocia a la tenencia patrimonial de la tierra.

${ }^{5}$ Estas nociones forman parte de la conceptualización de la espacialidad de los procesos sociales que plantea Coraggio $(1989,86)$, la cual señala que una forma espacial es aquella configuración territorial que acusa regularidad y recurrencia, y su sentido puede ser descifrado a partir de la lógica del proceso social correspondiente. 
interacción al interior de estos espacios lindados de residencia y productivo delimitados por cada configuración, que a la vez son ámbitos de propiedad del grupo. ${ }^{6}$ Estas configuraciones territoriales son relevantes porque albergan espacios colectivos de vida de los miembros del grupo de parentesco, donde ocurren -entre otras actividades- las prácticas de comunicación y manejo de café orgánico conforme al ciclo de este cultivo, las cuales tienen correspondencia con las categorías de comunicación lingüística y trabajo, intrínsecas a los llamados procesos de reproducción social por excelencia. $^{7}$

Se considera que en la base de la constitución del grupo doméstico se encuentran las prácticas patrilineales de residencia y herencia puesto que configuran el lugar donde habitan y trabajan sus miembros. Se usa el concepto de grupo doméstico (GD en adelante) para designar a la unidad social que habita una casa del complejo habitacional del grupo localizado de parentesco. ${ }^{8}$ Con ello se privilegia la corresidencia como un atributo destacado del GD (Bender 1976, 493,497 ) sobre el de parentesco que caracteriza a la familia (Bender 1976, 493; Laslet 1972). La noción de un mismo espacio de existencia, de cohabitación, es esencial en el GD (Segalen 1992, 37). La residencia común, la corresidencia implica una interacción constante entre los miembros del grupo de parentesco, y el atributo de proximidad espacial que caracteriza a los grupos corresidenciales permite deslindarlos de las funciones domésticas que tienen como referente funciones sociales (Bender 1976, 495), esto es, de las funciones de cooperación económica de producción y consumo agrícola que requiere la organización de actividades para el trabajo agrícola,

${ }^{6}$ La noción de ámbito de propiedad aquí se vincula con el concepto de apropiación que tiene como condición indispensable "una organización del espacio y un sentido de propiedad [...que implica] delimitación, lindes, separación entre dos trozos de espacio [...ya que] todo espacio social organizado está lindado" (George 1985, 41). En el contexto de formas de apropiación del territorio asentadas en la propiedad colectiva de pueblos originarios, los límites de los ámbitos de propiedad del grupo de parentesco y los límites internos de los espacios habitacionales y productivos usufructuados por los grupos domésticos no precisan de barreras físicas (bardas, alambres), al ser reconocidos por los miembros de la comunidad y del grupo.

${ }^{7}$ Esta temática se aborda de manera tangencial en este documento.

${ }^{8} \mathrm{El}$ GD puede estar constituido por una familia nuclear (padres e hijos) o extensa, y puede incluir otros miembros que no tengan lazos de parentesco. 
el manejo de recursos productivos o el consumo (Netting et al. 1984, xxi; Hammel 1984, 30). De esta manera se logra un distanciamiento de los criterios funcionalistas de producción y consumo con los cuales tradicionalmente se ha abordado al GD, que permite enfocar su carácter localizado y realizar una aproximación a la expresión espacial de las prácticas de parentesco.

Una mayor comprensión de las prácticas de parentesco implica no sólo dimensionarlas como normas o principios patrilineales; ya que en esa dirección se sitúa a los actores como sujetos que las internalizan, manteniéndolos subordinados a la determinación de un orden normativo inaccesible a su conciencia (Garfinkel 1967, citado por Santoro 2003, 245). Incorporar en la práctica o interacción social además de la aplicación de normas, la noción de poder, entendida como la capacidad transformadora de la acción, y de comunicación de sentido (Giddens 2001, 137, 150) ${ }^{9}$ proyecta al actor social como un agente reflexivo con un carácter electivo de una forma de vida. Bajo este enfoque, en los siguientes apartados se analizan las prácticas reproducidas de parentesco de residencia patrilocal y herencia patrilineal vinculadas con las configuraciones de las sedes colectivas de los ámbitos de residencia y productivo de los grupos de parentesco tseltales objeto de estudio; las sedes propician encuentros cotidianos o periódicos entre los miembros del grupo, que favorecen -entre otras actividades- la socialización de conocimientos de café orgánico en las comunidades tseltales.

\section{Práctica de Parentesco de RESIDENCIA PATRILOCAL Y CONFIGURACIÓN DEL ESPACIO COLECTIVO DE VIDA DE LA UNIDAD DE RESIDENCIA}

En este estudio se concibe al grupo localizado de parentesco (GLP en adelante) como un sistema de interacción social, entendiendo por sistema a "las relaciones reproducidas entre actores y colectividades

${ }^{9}$ Giddens plantea que la interacción social, vista como práctica reproducida, es disociada, sólo en términos analíticos, en relaciones de poder, moralidad y comunicación de sentido, las cuales están permeadas por modalidades de estructuración e implican respectivamente la aplicación de recursos, normas y el uso de esquemas de comprensión. 
organizadas como prácticas sociales regulares" (Giddens 2011, 61), y a las prácticas situadas de parentesco, residencia patrilocal y herencia patrilineal, como interacciones sociales.

La pareja fundadora del GLP tseltal ejerce una normativa patrilineal en la residencia y exogámica en la alianza matrimonial, ligada a relaciones de poder. El poder representa la capacidad del agente -la pareja fundadora- de movilizar o aportar recursos que se aplican como medios en una interacción, y es el "puede" que media entre intenciones o necesidades y la realización concreta de resultados (Giddens 2001, 138). El proceso de residencia patrilocal evidencia no sólo la movilización de recursos de asignación, ${ }^{10}$ constituidos por la dotación de terrenos donde los GD de consumo independiente ubican sus casas, sino que también muestra de manera paralela la movilización de recursos de autoridad ${ }^{11}$ que consisten en "la organización espacio-temporal de sendas y regiones de una vida diaria" (Giddens 2001, 285) de los miembros que articula el grupo de parentesco, derivada del establecimiento de los espacios habitacionales de los GD de los hijos en el vecindario del padre. ${ }^{12} \mathrm{El}$ proceso da como resultado la constitución de la sede colectiva del ámbito de residencia del GLP, configurada espacialmente por el complejo habitacional de las viviendas de los GD. A esta sede le denominamos Unidad de Residencia (UR en adelante), y constituye un espacio colectivo de vida de las tres generaciones de lazo patrilineal que integran al grupo de parentesco, que puede o no incluir a otros residentes. La sede implica un uso del espacio que provee escenarios de interacción, y es el lugar "donde intersectan las actividades de rutina de diferentes individuos" (Giddens 2001, 151), en el caso, las que realizan los miembros del GLP, entre las que se pueden encontrar las relacionadas con la comunicación de conocimientos de café orgánico. Los encuentros cotidianos de los miembros del GLP en su

${ }^{10}$ La movilización de recursos de asignación "denota formas de aptitud transformativa que generan mando sobre objetos, bienes o fenómenos naturales” (Giddens 2011, 69).

${ }^{11}$ La movilización de recursos de autoridad "denota formas de aptitud transformativa que generan mando sobre personas o actores" (Giddens 2011, 69).

${ }^{12}$ En la alianza matrimonial exogámica se movilizan recursos de autoridad que consisten en "la organización y relación de seres humanos en asociación mutua" (Giddens 2011, 69). 
UR se realizan en escenarios de interacción constituidos generalmente por espacios abiertos.

$\mathrm{Al}$ interior de los parajes Kotolté y Los Mangos, ${ }^{13}$ las ur se localizan tierra arriba $\left(A h k^{\prime} o l\right)$ o tierra abajo ( $A$ h lan). En la ur del grupo de parentesco de Kotolté, las viviendas de los GD de los hijos varones están distanciadas y se distribuyen en forma casi circular, a manera de satélites, en torno a la casa del padre; entre las casas hay espacios con árboles frutales y matas de café por lo que se interconectan mediante una red de pequeñas veredas, destacan las veredas que van a dar al patio de la vivienda de los abuelos. En cambio, la un del grupo de parentesco de Los Mangos está constituida por una sola casa, que presenta la misma composición de espacios habitacionales que la casa del miembro fundador del anterior grupo, tienen también áreas arboladas a su alrededor. La figura 1 representa las UR de estos grupos -las sedes colectivas del ámbito de residencia-, y la distribución de las casas a su interior que da cuenta del proceso de residencia patrilocal; las genealogías de los grupos registran los GD y miembros que los integran y su ubicación al interior de cada complejo habitacional.

La UR del GLP tseltal no se ajusta al concepto antropológico tradicional de residencia vinculado al criterio de "los que viven bajo el mismo techo", que algunos autores usan para definir al grupo de residencia (Verdon 1979; Slade 1976). Así definida, la residencia evoca una actividad cotidiana en espacios compartimentados. En la UR tseltal ocurre una situación distinta, ya que las actividades cotidianas de los miembros del grupo de parentesco transcurren en gran medida en escenarios de interacción constituidos por espacios abiertos, como son los patios de las casas de los GD y las áreas arboladas aledañas a ellas. Las casas principalmente se emplean para dormir o comer. El hecho de que la mayor distribución de encuentros de los miembros del grupo de parentesco se realice en espacios abiertos, nos lleva a considerar a la UR tseltal como un espacio social cuyos límites están dados por las fronteras de actividades cotidianas creadas por los miembros del grupo.

${ }^{13}$ La unidad de asentamiento indígena es el paraje, el cual sustenta un patrón de asentamiento disperso en el espacio alteño que contrasta con la organización urbana del espacio de la ciudad de San Cristóbal de Las Casas (Cervantes 2006, 156, 162). 


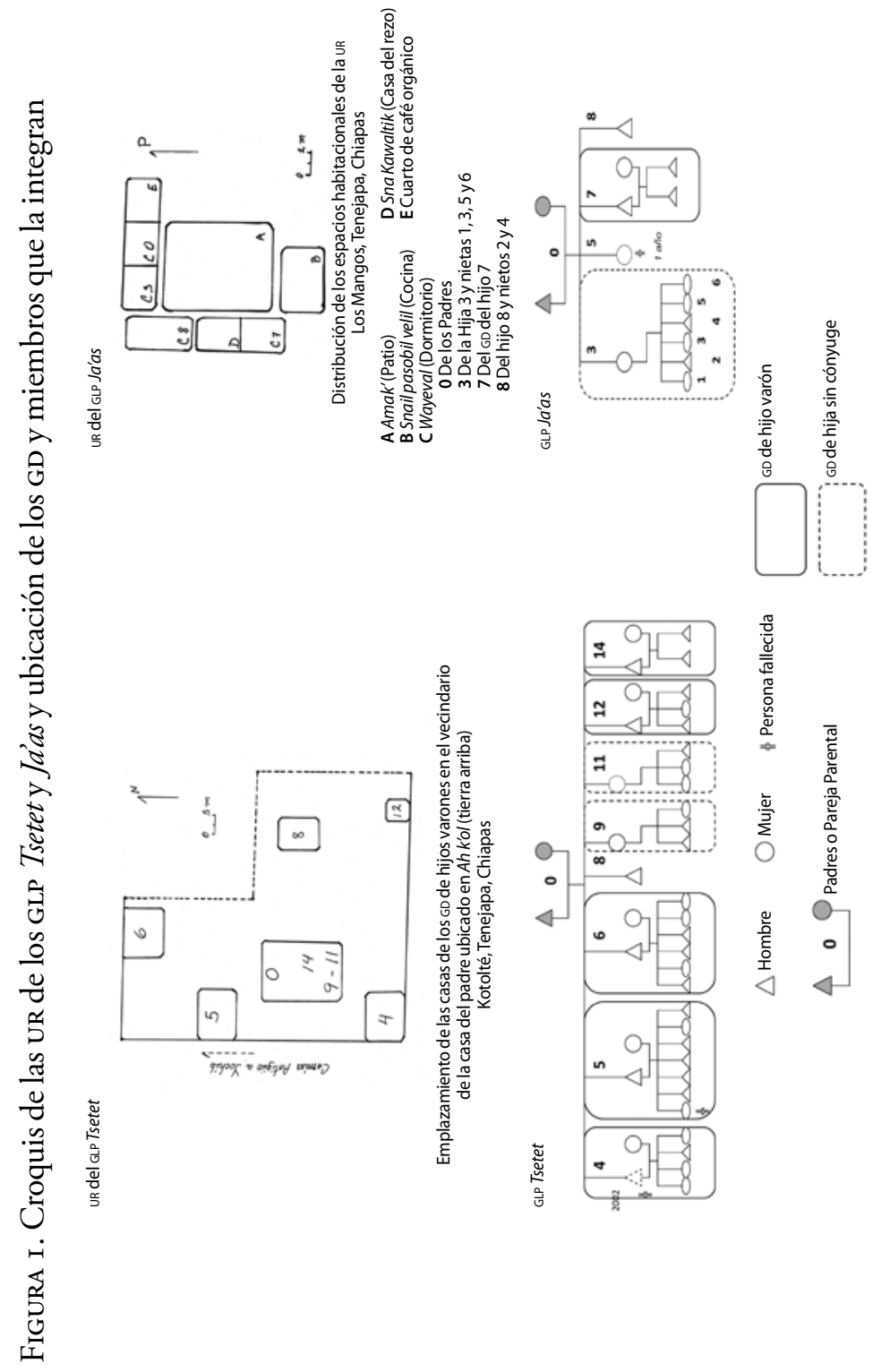


El espacio abierto, propiedad constante de los escenarios de interacción de los miembros del GLP, se expresa en la nomenclatura tseltal en el término jamalal, que sirve también para designar al espacio del patio de la casa del GD, el amak'. En los patios de las casas se descansa al término de las labores agrícolas, se seca el café obtenido en la cosecha por cada GD, se platica de manera cotidiana mientras juegan los niños. De la distribución de encuentros cotidianos de los miembros del grupo de parentesco al interior de la UR destaca, en mayor número, la que ocurre en el amak' del abuelo, se constituye así en el lugar de encuentro -tael bail-o lugar de reunión -tsob bail- de los miembros del grupo. El espacio íntimo de cada casa es la habitación o habitaciones usadas para dormir, y son denominadas wayeval, que se traduce por igual dormir o sońar. La cocina es designada en tseltal snail pasobil velil -la "casa" de la elaboración de la comida-, generalmente constituye una construcción rústica adyacente al wayeval, es un espacio colectivo donde se reúnen los miembros de cada GD independiente. ${ }^{14}$

La figura 2 presenta los croquis de las unidades sociales de residencia elaborados por los grupos. En la representación de la UR Los Mangos, al amak' se le traza como un articulador de los espacios habitacionales y es el de mayor dimensión. En la representación de la UR Kotolté, la mayor dimensión de la casa del padre responde a un amak'espacioso y al conjunto de GD que en ella vive (el del padre, el de su hijo menor y los de sus hijas sin cónyuge). ${ }^{15} \mathrm{La}$ dimensión genealógica del grupo de parentesco incide en el tamaño del sitio que ocupa la UR, sin embargo, lo común en ella es que la mayor parte de la vida cotidiana transcurre en los espacios abiertos que la configuran, lo que permite una frecuente interacción entre los miembros emparentados.

${ }^{14}$ En la casa de la pareja parental de los GLP observados, la de los abuelos, otro espacio importante es la habitación para rezar, aledaña a las habitaciones donde se duerme. En Kotolté, esta habitación presenta numerosas imágenes y esculturas de yeso cristianas para hacer oración, mientras que en la habitación de Los Mangos sólo se dispone de una cruz rústica de madera, herencia del abuelo paterno. En la primera se reza a Cristo, la virgen María y a diversos santos, en la segunda se reza a la madre tierra. Ambas habitaciones permanecen generalmente cerradas y se ocupan en encuentros especiales.

${ }^{15}$ La superficie del amak' de la uR Los Mangos tiene alrededor de $45 \mathrm{~m}^{2}$ mientras que el amak' de la casa de los abuelos en la uR Kotolté mide aproximadamente $70 \mathrm{~m}^{2}$. 


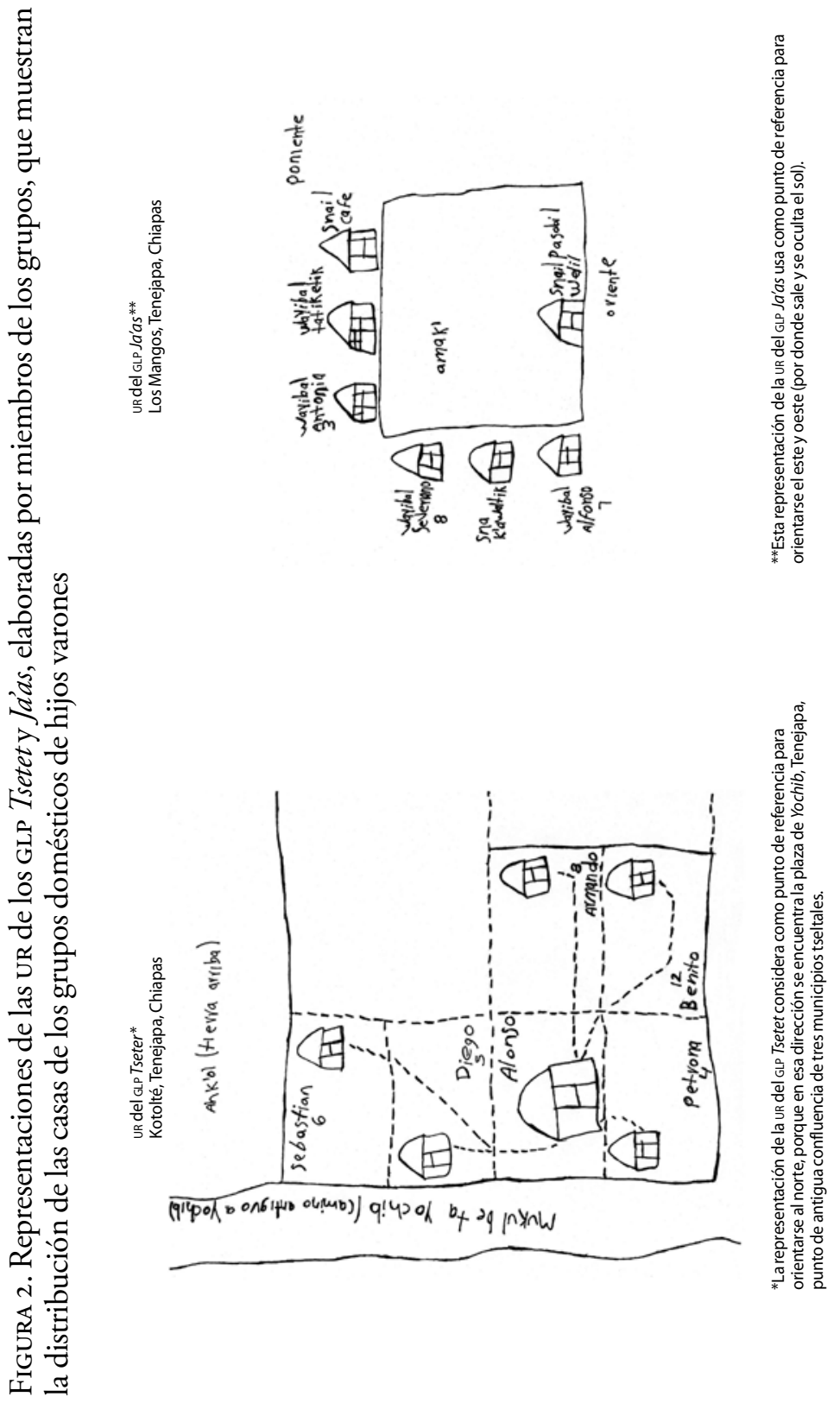


En términos generales, la UR constituye un espacio donde circula información, bienes y ayuda mutua. Y entre las rutinas de encuentro de los miembros del grupo de parentesco enlazadas con la comunicación cotidiana, se aborda y socializa, entre toda la diversidad de temas relacionados con el fluir de la vida diaria, aquellos relacionados con la dinámica del café orgánico, como aspectos de las labores de este cultivo realizadas en relación con el ciclo agrícola, la estimación de la calidad de la cosecha, el precio del café, etcétera. El GLP se revela entonces como una entidad de socialización importante, y se puede considerar que coadyuva a la socialización primaria del agente ante las numerosas interacciones de los nińos con su parentela al interior de la UR. Los miembros del grupo se sitúan socialmente a la vez respecto a su GD y a su propia parentela. Se coincide con Bender $(1976,502)$, quien señala que el proceso de socialización primaria no sólo requiere de la familia nuclear, sino también de unidades sociales más amplias.

En los parajes Kotolté y Los Mangos, dado el contexto de propiedad colectiva de las comunidades alteñas, los límites de las UR de los grupos de parentesco no están lindados por alambrado o bardas. La diferenciación interna y localización de estos grupos en la unidad de asentamiento indígena se da con base en el topónimo $A h$ k’ol (tierra arriba) o Ah lan (tierra abajo) y al jol bil (cabeza de nombre) del grupo adquirido patrilinealmente, antecedido del vocablo Tsobolbaltic (juntarse muchos). El vínculo entre el grupo y la UR, que evidencia una relación entre parentesco y territorio, se acuña en el término Tsobolbaltic Tsetet y Tsobolbaltic Ja'as ${ }^{16}$-respectivamente para los GLP Kotolté y Los Mangos-, que manifiesta a la vez un rasgo de identidad propia de cada grupo.

La información empírica evidenció un principio agnaticio ${ }^{17}$ en la constitución de las unidades sociales de parentesco tseltales. Tanto en la comunidad Kotolté como en Los Mangos se encontraron grupos de parentesco con el mismo jol bil que los GLP de nuestro interés, con residencia contigua a ellos y estructurados generalmen-

${ }^{16}$ Tsetet significa árbol cortado y Ja’as árbol de zapote.

${ }^{17}$ Agnaticio es un vínculo parental trasmitido vía varones. 
te de manera patrilineal. Los miembros varones de las parejas parentales de estos grupos corresponden a los hermanos de Alonso Tsetet-López y de Diego Ja'as-Girón -los abuelos de los GLP objeto de estudio-, pues, los padres de ambos ya murieron. Este conjunto de grupos de parentesco guarda semejanza con el grupo agnaticio localizado formado por varias patrilíneas limitadas localizadas a las que no le sobrevive algún pariente mayor que pueda ejercer una autoridad moral sobre el grupo (Robichaux 1995, citado por Estrada op. cit., 30).

Si bien, la UR del GLP se configura territorialmente a través de la residencia patrilocal, el sistema de interacción del grupo que ocupa el complejo habitacional en varios casos incluye GD de hijas casadas sin cónyuges - que habitan la casas de sus padres-como lo ilustran los GLP Tsetet y Ja'as (figura 1). Esta flexibilidad en la residencia tiene como antecedente la infracción a la norma patrilocal por parte del esposo de la hija casada. En la infracción se quebranta el nexo entre derechos y obligaciones inherente a una interacción, de manera tal que, siguiendo a Giddens $(2001,134)$, lo que es un derecho de un participante en un encuentro -el derecho de la esposa y sus hijos de residir en la UR de su esposo-, conforme a la práctica de residencia patrilocal, no se realiza porque el otro participante -el esposo- no responde apropiadamente con la obligación que le atañe. El incumplimiento de esta práctica no sólo deriva de la conducta de este último actor, sino que además refiere comúnmente a su falta de capacidad de contar con los medios, recursos o facilidades - tierra o trabajo para conformar un GD de consumo independiente- para que la acción social se produzca -la residencia patrilocal- (Giddens $2011,55)$. Esta situación conduce a la revisión de los contextos en que esta práctica de larga duración no se cumple.

Un contexto emergente en las comunidades alteñas es la migración de jóvenes casados en busca de trabajo que trastoca la residencia patrilocal y conduce generalmente a que sus esposas e hijos retornen a vivir en la UR de sus padres, como es el caso de los GD de las hijas casadas nueve y once del GLP Tsetet. Esta situación orilló a ambas hermanas a insertarse en el mercado laboral fuera de su comunidad, dejando a sus hijos al cuidado de los abuelos. La hija once 
emigró hace un tiempo hacia Estados Unidos por un periodo de cinco ańos y allí conoció a su actual pareja, proveniente de una comunidad tseltal, Tsibaltec, Tenejapa, donde ahora vive, mientras los niños y adolescentes de su primer matrimonio siguen viviendo con los abuelos maternos. La hija nueve ha venido trabajando por periodos cortos al año en la ciudad de México.

Un contexto inusual en las comunidades indígenas ocurre cuando el GD de un hijo varón no accede a un espacio productivo, vía herencia de la tierra. Situación que conduce a este GD a residir en la UR de sus suegros, como lo ilustra el GD de la hija tres del GLP Ja'as. La falta de un medio de vida -la tierra- que permitiera a este GD sobrevivir de manera independiente, así como la migración del cónyuge en busca de trabajo en 2006, cuando nació el último miembro del núcleo familiar -al igual que en los casos del GLP anterior-, reforzó que ella y sus hijos continuaran viviendo en la UR de sus padres. La posición del nacimiento de sus dos únicos hermanos (siete y ocho) también incide en la inicial instalación del GD en cuestión en la UR del grupo, pues, esto permitía incorporar mayor número de miembros en las labores agrícolas. En algunos parajes de Santa Marta, Chenalhó - una comunidad tsotsil de la región alteña-, Ixtacuy et al. (2006, 208-209) encuentra que “jóvenes parejas comienzan a establecer su residencia en terrenos de los padres de la esposa [...porque significa] mayor extensión de terrenos cultivados con café o maíz”. En la base de la transgresión de la norma patrilocal de residencia por parte del joven esposo se encuentra, al igual que el caso anterior, el contar con mayor número de miembros por parte del grupo de parentesco para realizar los trabajos agrícolas.

El sentido del incumplimiento de la práctica de residencia patrilocal por parte de los esposos de las hijas casadas es procesado de manera diferente por ambos grupos. En el GLP Ja'as, los padres argumentaron que la hija tres y su esposo fueron invitados a vivir con ellos desde que se casaron, y que cuando su esposo la abandonó decidieron que continuara viviendo con ellos junto con sus hijos. En el GLP Tsetet para los dos casos ya señalados, su papá argumentó que: 
antes nadie dejaba a la mujer porque era castigado [...] antes quedan las mujeres [solas] pero ya viudas, cuando ya se murió uno. Ahorita el tiempo cambio, jútale! muchos hombres lo dejan a las mujeres, hasta mujeres lo dejan a su marido, van con otro hombre [...] A menos que sea una persona brava, hay que ir hasta la cabecera si quiere uno echar pleito [porque devolvieron a una hija casada] [...] pero el castigo [para el muchacho] es poco [...] Yo no quise hacer pleito, mejor que esté aquí Mariana [hija nueve] y mis nietos [de Mariana e hija once]. ${ }^{18}$

En todos los casos, la estancia de las hijas y su descendencia en la UR de sus padres trastoca la norma patrilocal de residencia, situación que lleva a considerar a los elementos normativos de sistemas sociales como demandas contingentes puestas en vigencia en contextos de encuentros reales (Giddens 2011, 66).

\section{Práctica de PARENTESCO DE HERENCIA PATRILINEAL Y CONFIGURACIÓN DEL ESPACIO COLECTIVO DE VIDA DEL TERRITORIO PARCELARIO DE CAFÉ}

Una de las configuraciones espaciales que exhibe regularidad y recurrencia en las comunidades cafetaleras alteńas es el territorio parcelario de café del grupo de parentesco, formado por parcelas dispuestas habitualmente de manera contigua que son usufructuadas por GD independientes. Esta forma espacial no es más que la expresión de la práctica de parentesco de herencia patrilineal de la tierra, la cual se revela, al igual que la práctica de residencia patrilocal, como uno de los mecanismos reguladores del proceso de constitución de esta unidad socioterritorial.

En la herencia de la tierra, la pareja fundadora del GLP cede un espacio productivo, la parcela de cafetal, para que sea usufructuada por el GD del hijo varón. Al igual que en la residencia, esta práctica evidencia entonces una normativa patrilineal vinculada a una relación de poder ${ }^{19}$ ahora sostenida en la movilización o aporte de la

${ }^{18}$ Entrevista a Alonso Tsetet-López Guzmán, agosto de 2013.

${ }^{19}$ La noción de poder aquí se aplica como la capacidad transformadora de la acción social, y se concreta en la movilización o aporte de recursos aplicados como medios en la 
calidad de tierra del cafetal, la cual constituye un recurso de asignación (Giddens 2011, 69). Las calidades de tierra heredada (milpa, cafetal, etcétera), considerando los recursos genéticos que mantienen, son a la vez medio de producción y bienes producidos caracterizados como "artefactos creados por la interacción del recurso de la tecnología y un recurso ambiental" (Giddens 2011, 285). La peculiaridad de estos "bienes" deriva de que son resultado de largos procesos de domesticación, ${ }^{20}$ por ello, el mantenimiento de las calidades de tierra no puede ser adjudicado al quehacer de GD o APL aisladas. De ahí que la práctica de herencia de la tierra refiere necesariamente a un contexto de propiedad colectiva, que hace posible la relación orgánica entre usufructo y acceso a un recurso generado socialmente.

La agencia de la pareja fundadora del GLP se evidencia en la capacidad de transmisión de este recurso de asignación ejercida en la práctica de la herencia. Y mientras que en la herencia de las calidades de tierra de milpa ha privado "una continuidad en tiempo y espacio" (Giddens 2011, 52) en la región -es decir, desde época prehispánica-, en el café esta práctica ocurre ya entrado el último tercio del siglo xx, puesto que esta especie se introduce en las regiones indígenas a partir de la década de $1970 .{ }^{21}$ En la lógica campesina de la economía indígena, el cafetal en las parcelas de las comunidades alteńas viene a significar la obtención de ingresos en dinero anteriormente conseguidos mediante el peonaje realizado en las fincas cafetaleras del Soconusco. El café ancla, además, a los grupos de

interacción, constituyendo el "puede" que media entre intenciones y necesidades (Giddens 2001, 137-138).

${ }^{20}$ Así lo ilustra el caso del maíz nativo -matriz de las diferentes variedades indígenas actuales- que comprende 350 generaciones de selección y cultivo desde que se crearon los primeros linajes indígenas (Boege 2008, 170).

${ }^{21}$ Giddens hace referencia a la capacidad de continuidad en tiempo y espacio que presentan algunos sistemas sociales (Giddens 2001, 137-138). Aquí aplicamos esa noción no sólo a la práctica de la herencia de las calidades de milpa, sino también a la "estancia" de las sociedades mayances en Los Altos de Chiapas desde épocas prehispánicas hasta la actualidad. MacLeod $(1990,45)$ las ubica en el área maya como los pueblos mayas de las tierras altas, asentados en el macizo montañoso de los Cuchumatanes de Guatemala, cuya prolongación penetra en Chiapas en su extremo sur para luego formar el Alto Bloque Central (espacio de la región alteña). 
parentesco a la comunidad, rompe el ciclo migratorio a que orilla el peonaje y fortalece la copresencia de sus miembros al interior de este sistema de interacción.

Pese a ser una especie introducida, el cafetal adquiere la misma lógica mesoamericana que la milpa al establecerse como policultivo y rescatar una gran diversidad de recursos genéticos locales vinculados a preferencias y necesidades culturales del GD, pues, las especies presentes en él -aparte del café- responden a una diversidad de bienes y servicios ligados a un patrón de usos alimenticios, ornamentales, condimenticios, medicinales, rituales, maderables, etcétera. ${ }^{22}$ Esto ocurre sólo bajo el manejo del cafetal orgánico, promovido por organizaciones campesinas e indígenas, el cual sustituye al esquema institucionalizado de manejo del monocultivo de café bajo sombra monoespecífica impuesto por Inmecafé en el marco de la "revolución verde" (Pérez-Grovas 1999, 43, 47).

El uso de poder y la aplicación de normas son elementos intrínsecos a la interacción social en general; por ello no es posible separar reglas de los recursos que se aplican como medios en la producción y reproducción de una acción social (Giddens 2001, 133, 137-138). En este sentido, el recurso que se trasmite en la práctica de la herencia, las calidades de tierra -milpa, cafetal, etcétera-, se realiza de forma patrilineal y acotada de una generación a otra. ${ }^{23} \mathrm{~A}$ nivel social se producen grupos de "inspiración linajera" donde los hermanos varones tienen derechos iguales al patrimonio (Robichaux 2005a, 184). Esta práctica de parentesco se realiza en vida de la pareja parental del GLP, de tal manera que el acceso a la tierra por parte de los GD de los hijos varones posibilita su constitución como grupos de consumo independientes al usufructuar este medio de vida.

${ }^{22}$ Así lo ejemplifica el inventario de una parcela de un cuarto de hectárea de cafetal orgánico en la comunidad de Polhó, Chenalhó, Chiapas que reporta 45 especies diferentes al café (Pérez-Grovas 1999, 48).

${ }^{23} \mathrm{El}$ poder constituye un elemento clave en la noción de praxis; opuesto a algunos usos o abusos de la noción de poder, éste no implica la existencia de un conflicto, es el concepto de interés el que se relaciona directamente con el conflicto y la solidaridad (Pérez-Grovas 1999, 48). Así, la práctica en cuestión constituye una relación de solidaridad que se expresa en la capacidad de la pareja fundadora del grupo de ceder un espacio productivo para que sea usufructuado por el GD de un hijo varón. 
La transmisión unilineal de este recurso no necesariamente es resultado de la división de la parcela que recibió como herencia el fundador del GLP -en su anterior calidad de hijo varón casado-, puesto que en ocasiones éste realiza la compra de tierra -entre parientes u otros miembros de la comunidad-, cuando sus hijos son aún pequeños, como lo ejemplifica a continuación el testimonio de don Alonso Tsetet-López. Bajo estas circunstancias, las configuraciones espaciales del ámbito de propiedad del territorio parcelario del GLP que tienen el mismo jol bil no presentan la contigüidad que exhiben las UR de grupos de parentesco que integran grupos agnaticios.

vi que hay uno dos tres mis hijitos y empecé a pensar en comprar terreno y juntar paguita (dinero) [...] le compré a mi suegro dos y media hectárea [...] luego su hijo me vendió su herencia [de tierra] junté cuatro hectáreas, era k'altik [terreno arbolado], sembramos cacahuate, maíz, frijol [...] hasta después, como en el 85 empezamos a sembrar café, antes que yo otras personas ya tenían cafetal. ${ }^{24}$

La figura 3 representa los territorios parcelarios de café orgánico (тPCO) de los GLP objeto de estudio y la estructura genealógica de estos grupos resultado de la práctica de la herencia patrilineal de la tierra. Los límites del TPCo del grupo de parentesco y de las parcelas a su interior están demarcados por mojones apenas perceptibles denominados en tseltal s'akan, dando la imagen al observador externo de una continuidad de áreas arboladas.

El factor constante en la herencia patrilineal de la tierra es la estricta parcelación en partes iguales del terreno por heredar para evitar conflictos al interior del grupo, que además induce a la configuración de un terreno parcelado compacto ${ }^{25}$ que generalmente tiende a un mismo uso del suelo:

${ }^{24}$ Entrevista a Alonso Tsetet-López, julio de 2014.

${ }^{25}$ El patrón de herencia de la tierra hacia hombres y mujeres que se ejerce en Chamula-municipio tsotsil de la región alteńa-incurre en un mayor fraccionamiento de la tierra y configura un territorio parcelario familiar disperso, frecuentemente distribuido en distintas localidades que dificulta la organización del trabajo, induce a cambios en la residencia y a una fragmentación de los grupos de filiación, y frena formas de cooperación colectiva entre los miembros del grupo (Cervantes 2006, 152, 154). 


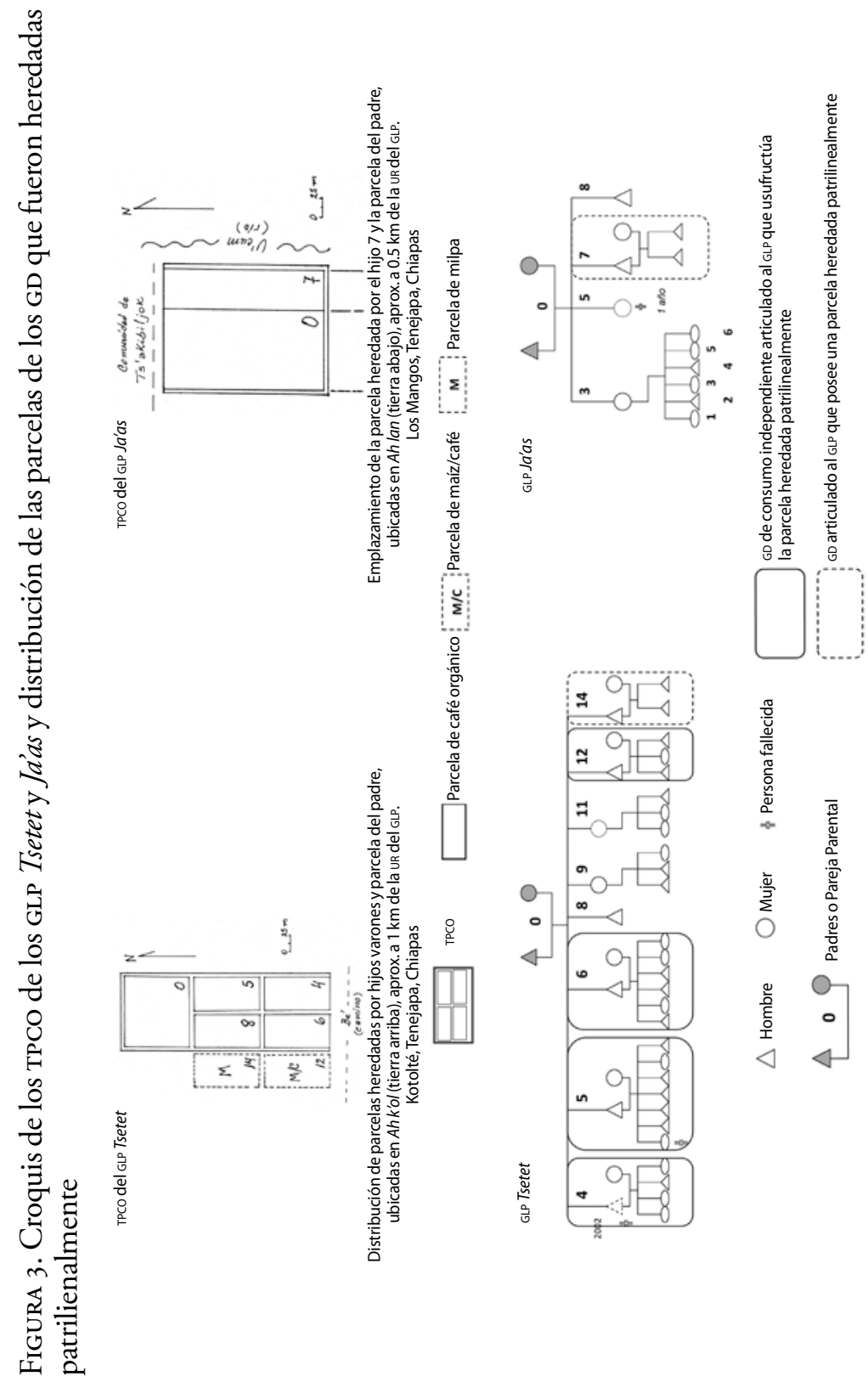


A nosotros (Diego Ja’as y sus cuatro hermanos) mi papá nos heredó una hectárea de monte y nos dijo que era para que sembráramos milpa [...] heredamos todos mis hermanos igual, una hectárea para maíz [...] solo a los hombres nos dieron herencia, a mi hermana María no [...] Una hectárea no alcanza, como fuimos comprando por eso fue creciendo la tierra [...] Al principio todos sembramos milpa, pero luego decidimos sembrar café, mis hermanos también sembraron café. ${ }^{26}$

A cada uno de mis hijos le di una parte igual del terreno, parejo para todos [...] si le toca a uno de más y a otro de menos hay problema y ffuerte el

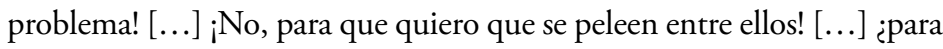
qué quiero yo problema? ${ }^{27}$

De esta manera, una de las formas espaciales que exhibe regularidad y recurrencia en las comunidades cafetaleras alteñas es el territorio parcelario de café (TPC) del GLP. La disposición contigua de las parcelas familiares adquiridas patrilinealmente, los límites de las parcelas demarcados por mojones apenas visibles -que, sin embargo, denotan una propiedad perfectamente deslindada-, el tamaño reducido de estos fundos (de un cuarto a una hectárea), y el manejo semiintensivo que requiere este cultivo propician que el espacio lindado de la forma espacial del TPC, se constituya -siguiendo a Giddens $(2011,151)$ - en una sede, esto es, en el lugar donde intersectan las rutinas de encuentro de los miembros del grupo de parentesco relacionadas con las prácticas de manejo del cultivo realizadas comúnmente por cada GD conforme al itinerario técnico del ciclo agrícola del café. El uso de este espacio provee escenarios de interacción que favorecen procesos de intercambio y transmisión de conocimientos del trabajo agrícola a "distintos niveles" - entre adultos, adolescentes y niños, entre miembros de la misma generación-, los cuales se encuentran en la base de la continuidad de las formas de manejo agrícola, del mantenimiento de las calidades de tierra y de la vigencia de conocimientos. Las pautas culturales de los procesos de

${ }^{26}$ Entrevista a Diego Ja’as-Gómez, julio de 2014.

${ }^{27}$ Entrevista a Alonso Tsetet-López, julio de 2014. 
comunicación en comunidades tseltales han sido ampliamente documentadas por Paoli $(2002,2006)$.

La formación de la sede del TPCO del GLP Tsetet, que viene a configurar un espacio colectivo de vida de los miembros emparentados, se deriva del paulatino cambio de uso del suelo que acompaña al proceso de herencia. La transición de uso del suelo se evidencia en la parcela con plántulas de café y maíz que recientemente heredó el hijo doce (figura 3), donde los ciclos anuales de milpa se mantendrán hasta el establecimiento de la plantación de café. El TPCO sustentado por las parcelas ya establecidas por parte del miembro fundador del grupo y los GD de sus hijos (cuatro, cinco, seis y ocho), evidencia el peso específico de las relaciones de parentesco en la cafeticultura orgánica de la región alteña.

El GLP Tsetet se adecúa a la caracterización de una agrupación supradoméstica localizada, que Nutini señala como una unidad social de parentesco intrínseca a la organización social mesoamericana contemporánea, donde los hijos casados establecen sus casas cerca de la casa paterna, formando grupos de consumo independientes, pero cooperan con el padre en una serie de actividades que pueden ir desde la producción agrícola hasta el coste de la celebración de rituales (Nutini 1976, citado por Robichaux 2005b, 306). Tal caracterización corresponde a una de las fases de un ciclo de desarrollo de grupos domésticos acorde con pautas culturales específicas, la fase de fisión. La diferencia en la configuración territorial de las UR tseltales - Tsetet y Ja'as- que se extiende a la forma en que cada grupo realiza los procesos de trabajo de café orgánico, denota diversos estadios del ciclo de reproducción social que serán discutidos en el siguiente apartado. Este enfoque del grupo corresidencial difiere de aquel que tradicionalmente lo ha enmarcado en el ciclo de la reproducción de fuerza de trabajo, forma de reproducción social propuesta por Chayanov, que identifica diferencias demográficas durante el ciclo de vida de la familia campesina como resultado de un balance entre producción y consumo.

La producción orgánica inscribe a los GLP tseltales objeto de estudio en nuevos andamiajes sociales que, al igual que en otras áreas cafetaleras indígenas, requiere la organización social para realizar la 
comercialización colectiva del grano y el fomento de su producción. Uno de ellos es la red social, que articula a estos y a otros grupos de parentesco de las comunidades de su área de influencia, que tiene como propósito generar y difundir conocimientos para innovar prácticas de manejo. Así, las estructuras de parentesco emergen en novísimas formas de organización social y coadyuvan a la generación de una producción alternativa, que sustenta a la vez -sus medios de vida- las calidades de tierra y su usufructo.

\section{Prácticas de parentesco, Reproducción social Y CONTEXTOS SOCIALES}

Las prácticas reproducidas de residencia y herencia, ejercidas bajo principios patrilineales, son parte significativa de la estructuración social del grupo localizado de parentesco. Vistas como procesos, constituyen los mecanismo de formación del grupo que dan cuentan de su génesis y evidencian que no es una unidad socioterritorial estática, sino una fase inscrita en el ciclo de desarrollo de grupos domésticos, la fase de fisión, lo que da pauta a considerar a la "familia o al grupo doméstico [...] desde la perspectiva de la reproducción social" (Robichaux 2002, 72).

La evidencia etnográfica en el área mesoamericana muestra un ciclo de desarrollo o sistema de formación de grupos domésticos común en ella: las fases de fisión, expansión y reemplazo del modelo de Meyer Fortes que se vinculan estrechamente con eventos específicos relacionados con la residencia basada en una lógica cultural (Robichaux 2005a, 195).$^{28} \mathrm{El}$ proceso de residencia patrilineal del GLP Tsetet, manifiesto en el establecimiento sucesivo de los emplazamientos de las casas de los hijos casados, ilustra la fase de fisión del ciclo (figura 4). En la casa de la pareja parental de este grupo reside

${ }^{28}$ En el modelo de Fortes, la fase de expansión [...] comienza con el matrimonio de dos personas hasta que completan su familia de procreación [...], corresponde al periodo durante el cual los hijos son económica, afectiva y jurídicamente dependientes de los padres. La fase de dispersión o fisión comienza con el matrimonio del hijo o la hija mayor y concluye con el último hijo o hija que se case. Finalmente, está la fase de reemplazo que termina con la muerte de los padres y la sustitución de la familia del último hijo en la estructura social (Fortes 1971, 4-5). 
Figura 4. Esquema de las fases del ciclo de desarrollo del grupo doméstico Tsetet vinculado al patrón de residencia patrilocal Kotolté, Tenejapa, Chiapas

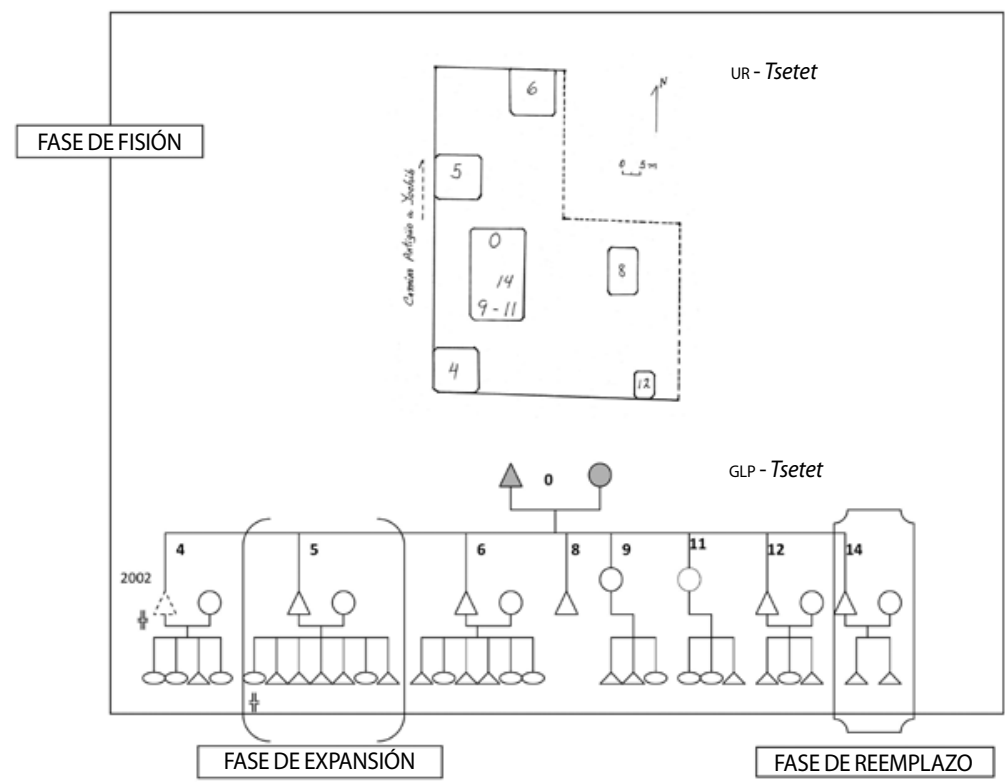

Fase de fisión: proceso de residencia de grupos domésticos de hijos varones en el vecindario de la casa del padre / formación UR-GLP Tsetet.

Fase de expansión: formación del grupo doméstico de cada hijo varón como grupo de consumo independiente y articulado al GLP: 4, 5, 6 y 12.

Fase de reemplazo: herencia de la casa del grupo doméstico fundador (GD 0 ) al grupo doméstico del último hijo (GD 14) por ultimogenitura patrilineal a la muerte de los padres.

el GD del hijo menor (hijo catorce), lo que podría configurar el acto de la herencia de la casa por ultimogenitura y constituir la fase de reemplazo en el proceso de reproducción social. La fase de expansión está representada en cada uno de los GD independientes de los hijos que habitan la unidad de residencia. La composición de espacios habitacionales de la uR del GLP Jáas evidencia el periodo de residencia del GD del hijo siete en la casa de sus padres $^{29}$-antes de

${ }^{29}$ Según Nutini $(1976,8)$ este periodo dura de uno a siete años. 
construir su vivienda en el vecindario de éstos-, así como expresa la constitución de una familia extensa. En el marco del ciclo de desarrollo de grupos domésticos, la familia extensa que integra al GLP Ja'as se puede considerar parte de la fase de fisión. La formación de GD como grupos de consumo independientes, la fase de expansión, requiere del binomio: acceso y usufructo de calidades de tierra (milpa, cafetal, etcétera). La conformación del territorio parcelario del GLP es inherente a la fase de fisión. ${ }^{30}$ Esto confirma el señalamiento que hace Robichaux $(2005 \mathrm{a}, 169)$ de que el proceso de herencia es una de las claves para comprender los procesos de reproducción social de grupos domésticos y localizados de parentesco.

La articulación estructural entre el GLP y el GD de la familia nuclear-formado por los padres e hijos-se revela tanto en el proceso de residencia patrilocal, que da origen a la UR, como en el proceso de herencia de la tierra patrilineal, que genera el TPC, y evidencia además la relación entre parentesco y componentes territoriales como un principio organizativo en la vida de la comunidad. El GLP tseltal opera procesos de administración del territorio bajo un contexto de propiedad colectiva-los concernientes a la residencia y herencia de la tierra- de socialización colectiva de conocimientos -en los espacios comunes de vida ya señalados-y en algunos casos de organización de servicios comunitarios para garantizar el asentamiento humano -en torno a los pozos de agua, en comunidades muy aisladas-.

Si los GLP Tsetet y Ja'as se proyectan en un periodo de tiempo mayor, las parejas parentales de estos grupos inicialmente fueron GD articulados a grupos de parentesco instaurados por sus padres. $\mathrm{Al}$ igual que los GD de sus hermanos se establecieron como un grupo de consumo independiente dentro de la vecindad de su padre por un periodo de tiempo, para luego formar su propio GLP manteniendo una residencia contigua con los grupos de sus hermanos y el jol bil adquirido patrilinealmente, es decir, para constituirse en un grupo agnaticio localizado. ${ }^{31}$ Las formas morfológicas que se pro-

${ }^{30}$ La visión de la propiedad de la tierra-territorio de los pueblos indígenas -asentada en la propiedad colectiva- integra propiedad, uso y administración de los recursos naturales en un solo sistema que es regulado como tal (Aguilar 2005, 160-161).

${ }^{31}$ En el poblado de Kotolté, Tenejapa, otros grupos agnaticios localizados tseltales 
ducen en el transcurso del ciclo de desarrollo de estos grupos domésticos, siguiendo a Robichaux $(2002,72)$, se rigen por principios específicos de la tradición cultural mesoamericana, a la que subyace un sistema de significados compartidos, que es inherente a toda cultura (Rodríguez 2006, 402), la cual puede "ser vista como soluciones socialmente heredadas a los problemas de la vida" (D'Andrade 1995, 249).

Si bien, la morfología de los grupos de parentesco tiende a reproducirse en el tiempo, las diferencias en los contextos sociales de una generación a otra imprimen cambios significativos en la dinámica de éstos. Así, en la generación anterior, el contexto de las comunidades de la región alteña, al igual que otras regiones indígenas calificadas como regiones de refugio, se caracterizaba por la interrelación entre las comunidades rurales y la agricultura capitalista de plantación (Bartra et al. 2011, 152-158; Nolasco 1985, 223-227), ejemplificada para Los Altos en la cafeticultura empresarial desarrollada por finqueros alemanes e italianos de la región del Soconusco, Chiapas (Pérez-Grovas 1999, 17). De esta manera, los GD de abuelos y las parejas parentales de los GLP actuales combinaban el trabajo estacional en el Soconusco con el de la parcela de milpa en sus comunidades de origen.

A partir de la década de 1970, el establecimiento de la cafeticultura indígena en las regiones del sureste del país, las de mayor aptitud para este cultivo, produce cambios en el contexto de la región alteña. Entre ellos, el anclaje de los grupos de parentesco a sus comunidades, derivado de la articulación de los ciclos de trabajo de milpa y cafetal y a su aporte respectivo de ingresos en especie y en dinero. La inercia mercantil y empresarial de la producción de café de grandes extensiones se trastoca en las nuevas áreas de producción y se supedita al manejo del minifundio y a la "racionalidad económica campesina" que, como señala Bartra et al. $(2006,22),{ }^{32}$

son Wowo (Jiménez), Moro (López), Xucuc (Hernández), Wacash (Jiménez), Tza’ ba (López). Y en Los Mangos, Tenejapa, entre otros grupos, son Moro (López), Wex (Pajarito), $B a$ ' (Mendez).

${ }^{32}$ La lógica de la producción cafetalera se estructura con base en la obtención de un "ingreso neto campesino", que consiste en la suma de ingresos en dinero, en especie y en 
valora el trabajo invertido a través de la suma de ingresos en especie, dinero y servicios.

Las comunidades cafetaleras alteñas, más adelante en la década de 1980, forman parte de las grandes movilizaciones nacionales de pequeños productores de café surgidas a raíz del súbito desmembramiento de la infraestructura estatal para el procesamiento y comercialización del café (Pérez-Grovas et al. 2002, 32). En ese escenario de ajustes económicos estructurales emergen numerosas organizaciones sociales cafetaleras campesinas e indígenas en el sureste del país, formando parte de "las oleadas de organizaciones sociales en el campo mexicano [que surgen] en el contexto de la globalización y la transición democrática” (De Grammont y Mackinlay 2006, 720). La creación de canales colectivos de comercialización es el planteamiento central de estas organizaciones, y en menor medida se proponen tareas de fomento y asistencia técnica enfocadas a la producción de café orgánico (Pérez-Grovas et al. 2002, 20). ${ }^{33}$ Estos planteamientos condujeron a la creación de nuevos andamiajes sociales que incluyeron la inserción de equipos de profesionistas para el logro de las tareas trazadas, que sustentaron en muchos casos procesos "híbridos" resultado de la vinculación del sustrato social indígena y los agentes de equipos técnicos; la producción orgánica es uno de ellos. En el caso que nos ocupa, el cultivo del café orgánico en la parcela y su procesamiento a nivel del GD se sustenta en procesos de generación y difusión de conocimientos desarrollados por una red social que tiene la peculiaridad de articular a los GLP de diversas comunidades que configuran el área de influencia de la organización cafetalera. El proceso de generación se realiza bajo la necesaria interdependencia de un conocimiento local (el de los grupos de parentes-

servicios en relación con las necesidades anuales de la familia (Bartra et al. 2006, 12-22). Los ingresos en especie provienen de los productos obtenidos en la milpa y del cafetal diversificado, mientras que los ingresos en dinero se obtienen de la venta del café, sumándose a ellos en ocasiones el trabajo asalariado.

${ }^{33}$ En el contexto internacional, la producción de café orgánico se encuentra alentada por una demanda de alimentos sanos por parte de los consumidores de Europa y Estados Unidos -basada en innovaciones tecnológicas adecuadas al medio ambiente ante la crisis generalizada de la agricultura tipo revolución verde-, y por la posibilidad de la creación de mecanismos de justicia comercial y equidad social. 
co) y un conocimiento aportado por miembros del equipo de profesionistas; la efectividad de este conocimiento híbrido se "mide" por el avance de la cafeticultura orgánica en el área de influencia geográfica de la organización social. Así, formas de organización social mesoamericana emergen en las nuevas formas organizativas de la red social y la organización cafetalera, que se enlaza a procesos globales implícitos en la comercialización internacional de este producto.

\section{Conclusiones}

Las prácticas de parentesco de residencia patrilocal y herencia patrilineal de la tierra consideradas como procesos sociales constituyen un principio de organización del territorio de los asentamientos tseltales al configurar los espacios de vida donde el grupo localizado de parentesco (GLP) habita y trabaja. Las configuraciones de estos espacios lindados, que son ámbitos de propiedad del grupo -asentados en la propiedad colectiva-, constituyen sedes caracterizadas por escenarios de interacción colectiva. En el espacio de vida de la unidad de residencia, circula información, bienes y ayuda mutua; y entre las rutinas de encuentro de los miembros del grupo enlazadas con la comunicación cotidiana, se aborda y socializa, entre otros temas, aquellos relacionados con la dinámica del café orgánico.

La sede del ámbito productivo, el territorio parcelario de café orgánico, es el lugar donde intersectan las rutinas de encuentro de los miembros del grupo vinculadas con las prácticas de manejo de este cultivo realizadas comúnmente por cada grupo doméstico, a la vez el uso de este espacio provee escenarios de interacción que favorecen procesos de intercambio y transmisión de conocimientos del trabajo agrícola a "distintos niveles" -entre adultos, adolescentes y nińos, entre miembros de la misma generación-, que están en la base de la continuidad de las formas de manejo agrícola, del mantenimiento de las calidades de tierra y de la vigencia de conocimientos.

El proceso de residencia patrilocal al configurar un complejo habitacional de las viviendas de los grupos domésticos articulados al grupo de parentesco incide en "la organización espacio-temporal de sendas y regiones de una vida diaria” (Giddens 2011, 285) de sus miembros. 
La herencia patrilineal de la tierra sustenta la transmisión y usufructo de las calidades de tierra generadas socialmente que incide en la independencia de los grupos domésticos que articula el grupo.

El GLP, visto como la fase de fisión de un ciclo específico de desarrollo de grupos domésticos, viene a reproducir ciclo a ciclo la configuración de los espacios colectivos de vida sustentados por las prácticas de parentesco abordadas. Sin embargo, los contextos sociales diferenciados de la región alteña imprimen cambios significativos en la dinámica de las comunidades; la cafeticultura indígena trastoca a la antigua "región de refugio", y la actual producción orgánica inscribe a estos grupos tseltales en nuevos andamiajes sociales de la organización social para realizar la comercialización colectiva del grano y el fomento de su producción. Así, las estructuras de parentesco mesoamericanas emergen en novísimas formas de organización social y coadyuvan a la generación de una producción alternativa, que sustenta a la vez -sus medios de vida- las calidades de tierra y su usufructo.

\section{REFERENCIAS}

Aguilar Rojas, Grethel. En busca de una distribución equitativa de los beneficios de la biodiversidad y el conocimiento indigena. San José Costa Rica: Unión para la Conservación de la Naturaleza (UICN), 2005.

Bartra Vergés, Armando, Rosario Cobo, Lorena Paz Paredes. Estudio sobre estrategias y economias familiares de comunidades cafetaleras de cinco regiones del sureste de México. México: Instituto Maya, 2006.

La hora del café, dos siglos a muchas voces. México: Comisión Nacional para el Conocimiento y Uso de la Biodiversidad (CONABIO), 2011.

Bender, Donald R. "A refinement of the Concept of Household: Families, Co-Residence and Domestic Functions". American Anthropologist. New Series 69(5) (1976): 493-504.

BOEGE, Eckart. El patrimonio biocultural de los pueblos indigenas de México. Hacia la conservación in situ de la biodiversidad y agrodi- 
versidad en los territorios indígenas. México: Instituto Nacional de Antropología e Historia, Comisión Nacional para el Desarrollo de los Pueblos Indígenas, 2008.

Bracamonte y Sosa, Pedro. "La jurisdicción cuestionada y el despojo agrario en el Yucatán del siglo xIx". Revista Mexicana del Caribe v(10) (2000): 150-179.

Cervantes Trejo, Edith. "Niveles de organización territorial de San Juan Chamula". En Ordenamiento Territorial Comunitario: un debate de la sociedad civil hacia la construcción de politicas públicas, comp. Fernando Anta, Arturo Arreola, Marco Antonio González y Javier Acosta, 151-168. México: Semanarp, INE, IDESMAC, Grupo Autónomo para la Investigación, Methodus, Servicios Alternativos, 2006.

Collier, George Allen. Planos de interacción del mundo tzotzil. Bases ecológicas de la tradición en los Altos de Chiapas. México: Instituto Nacional Indigenista, Secretaría de Educación Pública, 1976.

Coraggio, José Luis. "Sobre la espacialidad social y el concepto de región”. En Seminario sobre la cuestión regional en América Latina. Quito: Centro de Investigaciones, 1989, 67-105.

D'Andrade, Roy. The Development of Cognitive Anthropology. Cambridge: The Cambridge University Press, 1995.

Estrada Lugo, Erin Ingrid Jane. El parentesco maya contemporáneo: grupo doméstico y usos del parentesco entre mayas de Quintana Roo, México. Saarbrücken: Editorial Académica Española, 2011.

ForTEs, Meyer. "Introduction". En The Developmental Cycle in Domestic Groups, ed. Jack Goody, 1-14. Cambridge: The Cambridge University Press, 1971.

GeOrge, Paul. La acción del hombre y el medio geográfico. Colección Historia, Ciencia, Sociedad, núm. 61. Barcelona: Península, 1985. Giddens, Anthony. Las Nuevas reglas del método sociológico: critica positiva de las sociologías comprensivas. $2^{\mathrm{a}}$ ed. Trad. de Salomón Merener. Buenos Aires: Amorrortu, 2001.

- La constitución de la sociedad: bases para la teoría de la estructuración. 2a ed. Trad. de José Luis Etcheverry. Buenos Aires: Amorrortu, 2011.

GimÉnEz, Gilberto. "El problema de la generalización en los estu- 
dios de caso". Cultura y Representaciones Sociales, año 7(13) (2012): 40-62.

De Grammnot, Hubert C. y Horacio Mackinlay. "Las organizaciones sociales campesinas e indígenas frente a los partidos políticos y el Estado, México 1938-2006". Revista Mexicana de Sociología 68(4) (2006): 693-729.

Hammel, Eugene A. "On the *** of Studying Household Form and Function". En Households: Comparative and Historical Studies of the Domestic Group, ed. R. M. Netting, R. R. Wilk y E. J. Arnould, 29-43. Berkeley: University of California Press, 1984.

Ixtacuy López, Octavio, Erin Ingrid Jane Estrada Lugo, Manuel Roberto PARRA VÁzQuez. "Organización social en la apropiación del territorio: Santa Marta, Chenalhó, Chiapas", Relaciones. Estudios de Historia y Sociedad, XXviI(I o6) (primavera 2006): 183-219.

Laslett, Peter. "Introduction: The History of the Family". En Household and Family in Past Times Publications, ed. P. Laslett y R. Wall, 1-90. Cambridge: The Cambridge University Press, 1972.

MacLeod, Murdock J. Historia Socio-Económica de la América Central Española: 1520-1720. Guatemala: Editorial Piedrasanta, 1990.

Netting, Robert McC., Richard R. Wilk y Eric J. Arnould, "Introduction". En Households: Comparative and Historical Studies of the Domestic Group, ed. R. M. Netting, R. R. Wilk y E. J. Arnould, XIII-XxxvIII. Berkeley: University of California Press, 1984.

Nolasco, Margarita. Café y sociedad en México. México: Centro de Ecodesarrollo, 1985.

Nutini, Hugo. "Introduction: The Nature and Treatment of Kinship in Mesoamerica". En Essays on Mexican Kinship, ed. H. Nutini, P. Carrasco y J. Taggart, 3-77. Pittsburgh: University of Pittsburgh Press, 1976.

Paoli Bolio, Antonio. "Autonomía, socialización y comunidad tzeltal”. Reencuentro (33) (2002): 53-65.

. "Aprender la lengua y la cultura tzeltal". Reencuentro (47) (2006): 55-63. 
Peniche Moreno, Paola. "Grupos de filiación y movilidad poblacional. Los ch’ibales y la migración de los mayas en el siglo XVIII". Desacatos (13) (2003): 32-45.

PÉrez-Grovas Garza, Víctor. Evaluación de la sustentabilidad del sistema de producción de café orgánico en la Unión de Ejidos Majomut en la región de Los Altos de Chiapas. Tesis de Maestría, Universidad Autónoma Chapingo, 1998.

. “Café orgánico”. Revista Pronatura (5) (1999): 46-49.

Pérez-Grovas Garza, Víctor, Edith Cervantes Trejo, John Burstein, Laura Carlsen y Luis Hernández Navarro. El café en México, Centroamérica y el Caribe. Una salida sustentable a la crisis. México: Publicación CNOC y COOPCAFÉ, 2002.

RoBichaux, David. "Principios patrilineales en un sistema bilateral de parentesco: residencia, herencia y sistema familiar mesoamericano". En Familia y parentesco en México y Mesoamérica: unas miradas antropológicas, comp. David Robichaux, 167-272. México: Universidad Iberoamericana, 2005a.

“¿Dónde está el hogar? Retos metodológicos para el estudio del grupo doméstico en la Mesoamérica contemporánea”. En Familia y parentesco en México y Mesoamérica: unas miradas antropológicas, comp. David Robichaux, 295-329. México: Universidad Iberoamericana, 2005b.

. "El sistema familiar mesoamericano y sus consecuencias demográficas”. Papeles de Población (32) (2002): 60-95.

Rodríguez Salazar, Tania. "Cultura y cognición: entre la sociedad y la naturaleza”. Revista Mexicana de Sociología 68(3) (2006): 399-430.

SAntoro, Pablo. "El momento etnográfico: Giddens, Garfinkel y los problemas de la etnosociología”. Revista Española de Investigaciones Sociológicas (Reis) (103) (2003): 239-255.

Segalen Martine. Antropología histórica de la familia. Madrid: Taurus Ediciones, 1992.

Slade, Doren. "Kinship in a Nahuatl-speaking Community". En Essays on Mexican Kinship, ed. Hugo Nutini, Pedro Carrasco y James Taggart, 155-186. Pittsburgh: University of Pittsburgh Press, 1976. 
Verdon, Michael. "Sleeping Together: The Dynamics of Residence among the Abutia Ewe". Journal of Anthropological Research, vol. 35 (1978): 401-425.

ViLla Rojas, Alfonso. "Parentesco y nahualismo en una comunidad tzeltal del sureste de México". En Antropología mesoamericana, comp. Víctor Manuel Esponda, Sophia Pincemin y Mauricio Rosas, 73-90. Tuxtla Gutiérrez: 1992.

Vogt, Evon Z. Los zinacantecos, un pueblo tzotzil de los altos de Chiapas. México: Instituto Nacional Indigenista, 1966.

Yin, Robert K. Case Study Research. Londres: Sage, 2009. 